\title{
Karyomorphological Analysis and Phylogenetic Relationship of Gossypium L Species
}

\author{
K. P. M. Dhamayanthi* \\ Central Institute for Cotton Research Regional Station, Coimbatore-641003, Tamil Nadu, India
}

Received June 17, 2005; accepted October 24, 2005

\begin{abstract}
Summary Karyomorphological analysis of seven Gossypium species belonging to 'A' (G. arboreum, G. herbaceum), 'D' (G. aridum, G. armourianum, G. davidsonii), 'AD' (G. hirsutum, G. barbadense) genome was carried out. All the species invariably shows the basic chromosome number as $\mathrm{x}=13$. The chromosome size ranged from 1.1 to $4.7 \mu \mathrm{m}$. G. aridum had the smaller mean chromosome length $(1.15 \mu \mathrm{m})$ while $G$. barbadense had the larger chromosome $(4.7 \mu \mathrm{m})$. Karyotypes were of symmetrical type possessing long and short chromosomes in equal proportions. The satellite chromosomes were located in the long arm of one or two metacentric pair. The species varied with regards to number of SAT chromosomes and chromosome carrying secondary constrictions. Cluster analysis was done to group the species. It shows that the cotton species studied falls in to three distinct clusters. Results also revealed that the popular, cultivated American cotton $G$. hirsutum, and the Egyptian cotton G. barbadense might have originated from the crosses between the Asiatic cotton G. arboreum, G. herbaceum ('A' genome) and the American wild cotton $G$. aridum, G. armourianum, G. davidsonii ('D' genome). The present finding clearly indicates the genomic differences within the diploid species and between the diploid-tetraploid species of cotton can be utilised in hybridization programmes. Crossing of the species placed in distant clusters are suggested.
\end{abstract}

Key words Gossypium, Karyomorphology, Genome, Phylogeny, Cluster analysis.

Cotton (Gossypium L) is the world's leading vegetable fibre crop providing about $55 \%$ of all fibre used in textiles. The genus Gossypium is a rich source of many desirable genes for cotton improvement and it comprises 50 tropical and sub tropical species of diploid $(2 n=2 x=26)$ and allotetraploid $(2 n=4 x=52)$, indigenous to arid and seasonally arid regions (Endrizzi 1983, Fryxell 1992). Wild species of cotton provide useful traits such as special and superior fibre properties, cytoplasmic male sterility, resistance to biotic and abiotic stress etc. that can be introgressed in to the cultivated species for crop improvement. Since the variability available in cultivated germplasm is limited and it has been exhaustively utilised in breeding programmes, it has become a necessity to develop basic germplasm materials enriched with rare useful genes from wild species through introgression. However the ploidy level of wild genetic source and cultivated species is a strong barrier impeding gene exchange between these two group of species. Knowledge of the cytogenetic relationship between cultivated species and their allied wild relatives has proved to be essential in utilizing the desirable germplasm in an effective manner through hybridization. Karyotypic analysis of species is very useful in detecting the probable relationship, origin and nature of chromosomal variations in any crop. Further cytological characterization and karyotypic variations are very important for genetic manipulation of species. Though appreciable extent of cytogenetic research on genome homology and chromosome pairing has been reported in the genus Gossypium, no detailed systematic and precise karyomorphological studies of different species of Gossypium were carried out dur-

\footnotetext{
* Corresponding author, e-mail: cicrngp@redittmail.com
} 
ing the recent past due to the technical difficulties encountered in cytological manipulations of somatic cells. Hence the present investigation was taken up in seven species of Gossypium including three wild and four cultivated species to analyse the karyotypes that enhance the basic understanding of the interspecific variations and phylogenetic relationship between the species.

\section{Materials and methods}

Fresh seeds of four cultivated species and three wild species of cotton were collected from the germplasm of Central Institute for Cotton Research, Regional Station, Coimbatore during 20032004. Delinted seeds were germinated in petridishes and freshly grown roots were used for karyological preparations. Cytological observations were made primarily in mitotic cells of the root tips obtained from germinating seeds. The roots were prefixed in 8-hydroxy quinoline for $3 \mathrm{~h}$ and fixed in $\mathrm{OH}$ fixative (methanol : chloroform : picric acid; $6: 3: 1$ ) for overnight and hydrolysis was done in $1 \mathrm{~N} \mathrm{HCl}$ for $20 \mathrm{~min}$ at $60^{\circ} \mathrm{C}$ and stained in $2 \%$ aceto-orcein. Microphotographs were taken with suitable metaphase plates and these were used for karyotypic analysis. Karyotypic description was made based on the nomenclature suggested by Leven et al. (1964). For elaboration of the idiograms estimated chromosome measures were used from ten metaphase plates of 8-10 individuals for each species. The cluster analysis was carried out by Weighted Pair Group Method (WPGM). Phenogram was performed to group karyotypically similar species.

\section{Results}

The somatic chromosome number, karyotypic formula and size of the satellite chromosome of seven species of Gossypium are presented in Table 1. All the species of Gossypium presented the basic chromosome number $x=13$. Among the seven species, two were allotetraploid with $2 n=2 x=$

Table 1. Chromosome number, karyotypic formula and size of the SAT region in Gossypium species

\begin{tabular}{lcccc}
\hline \hline \multicolumn{1}{c}{ Species } & $2 n$ & Ploidy level & Karyotype formula & SAT- size \\
\hline G. hirsutum & 52 & $4 \mathrm{x}$ & $24 \mathrm{~m}+28 \mathrm{sm}$ & $0.2-0.7$ \\
G. barbadense & 52 & $4 \mathrm{x}$ & $26 \mathrm{~m}+24 \mathrm{sm}+2 \mathrm{ac}$ & $0.1-0.3$ \\
G. arboreum & 26 & $2 \mathrm{x}$ & $14 \mathrm{~m}+12 \mathrm{sm}$ & $0.2-0.8$ \\
G. herbaceum & 26 & $2 \mathrm{x}$ & $18 \mathrm{~m}+8 \mathrm{sm}$ & $0.2-0.5$ \\
G. aridum & 26 & $2 \mathrm{x}$ & $14 \mathrm{~m}+12 \mathrm{sm}$ & $-1-0.3$ \\
G. armourianum & 26 & $2 \mathrm{x}$ & $16 \mathrm{~m}+10 \mathrm{sm}$ & $0.2-0.4$ \\
G. davidsonii & 26 & $2 \mathrm{x}$ & $14 \mathrm{~m}+12 \mathrm{sm}$ & \\
\hline
\end{tabular}

$\mathrm{m}=$ median, $\mathrm{sm}=$ sub median, $\mathrm{ac}=$ acentric.

Table 2. Details of karyotypes in seven species Gossypium

\begin{tabular}{lrrrrrl}
\hline \hline \multicolumn{1}{c}{ Species } & $\mathrm{TCL} \pm \mathrm{SE}(\mu \mathrm{m})$ & $\mathrm{L}$ & $\mathrm{S}$ & $\mathrm{L} / \mathrm{S}$ & $\mathrm{X}$ & $\mathrm{CI} \pm \mathrm{SE}$ \\
\hline G. hirsutum & $133.57 \pm 1.86$ & 3.3 & 1.2 & 2.8 & 4.5 & $41.14 \pm 0.28$ \\
G. barbadense & $144.64 \pm 5.40$ & 3.5 & 1.1 & 3.2 & 4.6 & $40.87 \pm 0.12$ \\
G. arboreum & $70.26 \pm 5.84$ & 4.7 & 1.9 & 2.4 & 6.6 & $41.60 \pm 0.31$ \\
G. herbaceum & $71.10 \pm 1.05$ & 3.9 & 1.8 & 2.1 & 5.7 & $43.03 \pm 0.16$ \\
G. aridum & $70.96 \pm 6.95$ & 2.4 & 1.2 & 2.0 & 3.6 & $41.92 \pm 0.24$ \\
G. armourianum & $64.32 \pm 7.45$ & 3.5 & 1.5 & 2.3 & 5.0 & $41.12 \pm 0.28$ \\
G. davidsonii & $52.02 \pm 6.19$ & 2.9 & 1.4 & 2.1 & 4.5 & $42.15 \pm 0.31$
\end{tabular}

$\mathrm{TCL}=$ Total chromosome length, $\mathrm{L}=$ longest chromosome, $\mathrm{S}=$ shortest chromosome $(\mathrm{S}), \mathrm{X}=$ mean chromosome length, $\mathrm{CI}=$ centromeric index. 

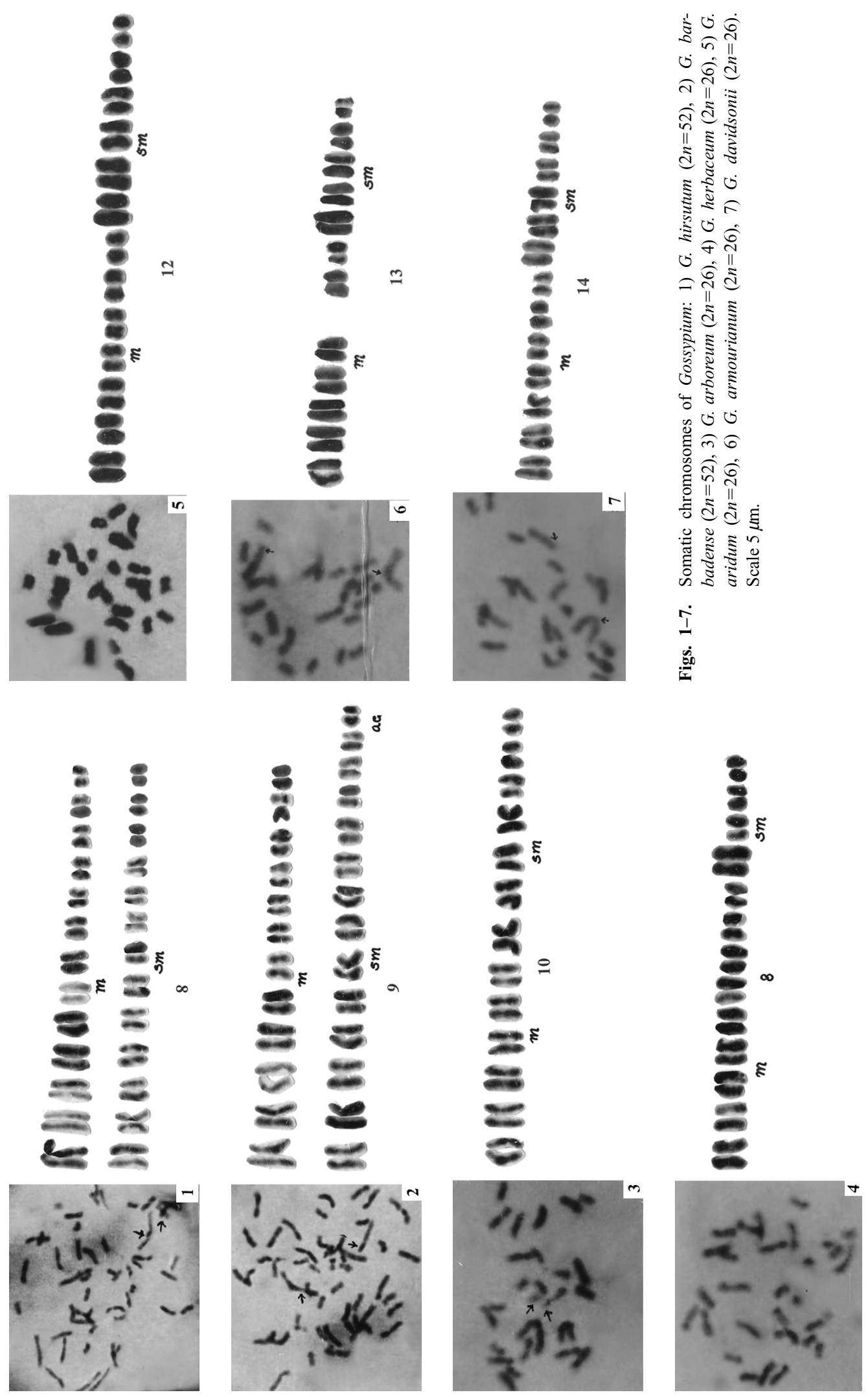


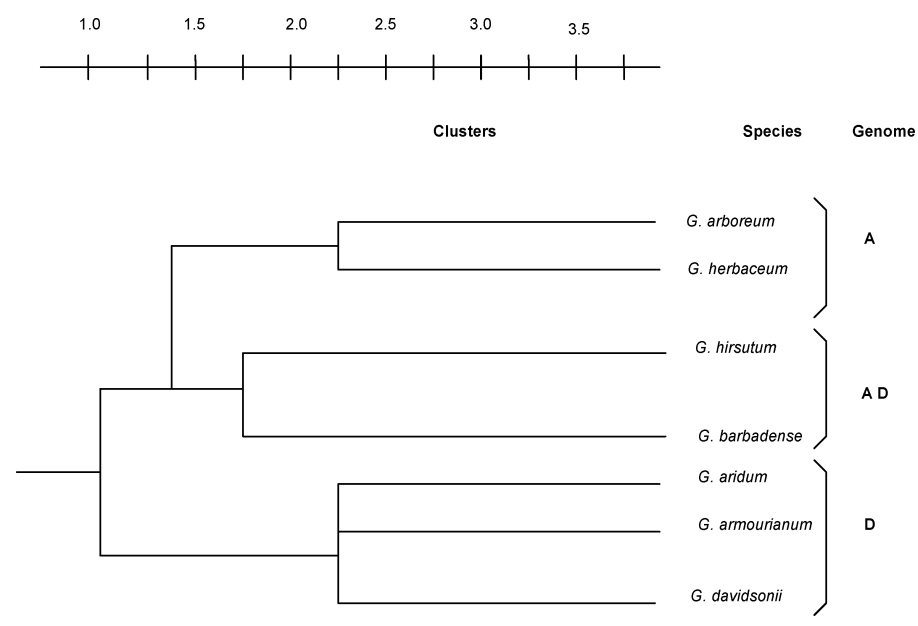

Fig. 8. Phenograms of seven of species Gossypium: G. hirsutum $(2 n=52)$, . barbadense $(2 n=52), G$. arboreum $(2 n=26)$, G. herbaceum $(2 n=26)$, G. aridum $(2 n=26)$, . armourianum $(2 n=26), G$. davidsonii $(2 n=26)$.

52 (Figs. 1, 2) and other five species were diploids $2 n=2 \mathrm{x}=26$ (Figs. 3-7). Details of karyotypes are presented in Table 2. The highest total chromosome length occurred in G. barbadense $(144.65 \mu \mathrm{m})$ and the least in G. aridum $(52.02 \mu \mathrm{m})$. The chromosome of allotetraploids ranged in size from 0.9 to $2.8 \mu \mathrm{m}$ and the diploids were ranged from 1.1 to $2.9 \mu \mathrm{m}$. The allotetraploid cotton species $G$. hirsutum have equal number of median and sub median chromosomes with the total chromosome length of $133.57 \mu \mathrm{m}$ while $G$. barbadense have 13 pairs of median and 12 pairs of sub median and a single pair of acentric chromosomes with the total chromosome length of $144.64 \mu \mathrm{m}$. The diploid Asiatic cotton species G. arboreum have seven pairs of median and 6 pairs of sub median chromosomes with the total chromosome length of $70.26 \mu \mathrm{m}$ while, G. herbaceum have 9 pairs of median and 4 pairs of sub median chromosomes with the total chromosome length of $71.10 \mu \mathrm{m}$. The wild diploid species G. aridum have 7 pairs of median and 6 pairs of sub median chromosomes and does not have any SAT regions or secondary constrictions with the total chromosome length at par with G. arboreum, while G. armourianum and G. davidsonii have SAT regions and secondary constrictions of one each in the longest pair with the total chromosome length of $64.32 \mu \mathrm{m}$ and $52.02 \mu \mathrm{m}$ respectively. SAT regions vary in size from 0.29 to $0.73 \mu \mathrm{m}$.

\section{Discussion}

Davie (1935) recorded the somatic chromosome length of $G$. hirsutum ranged between $0.8 \mu \mathrm{m}$ and $1.8 \mu \mathrm{m}$ and in G. herbaceum 1.1 to $3.2 \mu \mathrm{m}$. Gennur et al. (1988) reported the occurrence of $8.27 \mu \mathrm{m}$ metacentric, $4.61 \mu \mathrm{m}$ submetacentric and $0.11 \mu \mathrm{m}$ of acentric chromosomes in Asiatic cotton $G$. herbaceum. The relative chromosome size for the genomic groups of cotton has been classified earlier by Stephens (1947), Fryxell (1979b) which are at par with the present findings. The level of chromosome homology between the American cotton G. hirsutum and Egyptian cotton $G$. barbadense is very narrow as both the species possess 'A' and ' $D$ ' genomes. However, the cultivated Asiatic diploid cotton species shows significant variation in their chromosome morphology with the wild American diploid species as they possess small chromosomes ranges from 1.1 to $2.3 \mu \mathrm{m}$.

Karyotypes were of symmetrical type having almost equal number of larger and small chromosomes in allotetraploids. The karyomorphological features of both cultivated and wild diploid genome shows close similarity with the genomes present in allotetraploid species (Meshram, 1989). In general, 'A' genomes have large chromosomes and ' $D$ ' genomes have small chromosomes. 
Species with ' $D$ ' genome were found to have the least amount of evolutionary advancement thus suggesting that the small ' $D$ ' genomes are closest to the ancestral or prototype genome (Skovsted 1934 and Fryxell, 1979a). It is presumed that divergence of the diploid species is very ancient occurring no later than the cretaceous period (Fryxell 1979a).

Satellites were located in the longest chromosome of the haploid set possessed the secondary constriction of $G$. hirsutum and the first and second longest chromosome of G. barbadense, while in the diploid species it was found in the longest chromosome in G. herbaceum and G. armourianum. The presence of SAT was not a constant feature in the entities analysed, since no satellite were found in 25-30\% of the metaphase plates examined. Mosoud Sheidi et al. (1996) studied the karyotypes of $G$. herbaceum cultivars and recorded high genomic variability among the cultivars studied. However, in the present study only the tetraploid species G. barbadense showed the acentric pair, which might have originated from the diploid Asiatic species G. herbaceum due to gene introgression. The range of L/S ratio (2.1-3.2) indicating the occurrence of structural changes of chromosomes among the cultivars and points towards their distinctness. From a cytological view point, though the seven entities seem to constitute a relatively homogenous group, considerable amount of variation has occurred with in the wild and cultivated diploid species and diploids and tetraploid species of Gossypium, which can be utilized for the breeding programmes. Results obtained revealed that the allotetraploids of cultivated American species (G. hirsutum) and the Egyptian cotton species ( $G$. barbadense) might have obtained between the crosses of 'A' genome of Asiatic cotton species viz. G. arboreum and G. herbaceum and the ' $\mathrm{D}$ ' genome of American wild species viz. G. aridum. G. armourianum and G. davidsonii. Cluster analysis was done to group the species and measure the similarities between the species (Fig. 8). The species of Gossypium falls in to three distinct groups. Hybridization of the species placed in distant clusters is suggested.

\section{References}

Davie, J. H. 1935. Chromosome studies in the Malvaceae and certain related families. II Genetica 17: 487-498.

Endrizzi, J. E. 1983. Origin of allotetraploid species of Gossypium. In: Cytogenetics of crop plants. Edn. Macmillan India Ltd., New Delhi. pp. 441-45.

Fryxell, P. A. 1979a. The Natural History of the Cotton Tribe. Texas A \& M University Press, College Station.

- 1979b. Phenotypic analysis and the phylogeny of the diploid species of Gossypium L (Malvaceae). Evolution 25: 554-562.

- 1992. A revised taxonomic interpretation of Gossypium L (Malvaceae). Rheedea 2: 108-16.

Gennur, M. N., Habib, A. F., Kadapa, S. N. and Goud, J. V. 1988. Karyomorphological studies in Asiatic cottons. I. Karyotypic analysis of species and races of Asiatic cottons based on chromatin content. Cytologia 53: 97-106.

Levan, A., Fredga., K. and Sandberg, A. 1964. Nomenclature for centromeric position on chromosomes. Hereditas 52: 201-220.

Sheidi, M., Vojdani, P. and Alishab, O. 1996. Karyological studies in Gossypium herbaceum cultivars of Iran. Cytologia 61: 365-374.

Meshram, L. D. 1989. Cytogenetics of allopolyploids in cotton (Gossypium species). Ph. D. Thesis. P. K. Akola.

Stephens, S. G. 1947. Cytogenetics of Gossypium and the problem of the origin of new world cottons. Adv. Genet.1: 431442.

Skovsted, A. 1934. Cytogenetic in relation to plant breeding in cotton. Emp. Cotton. Grow. Crop., Rep. 2nd Conf., 46-49. 